\title{
Demo: A Mobile Platform for Event-Driven Donations Using Smart Contracts
}

\author{
Ludwig Trotter ${ }^{1}$, Mike Harding ${ }^{1}$, Chris Elsden $^{2}$, Nigel Davies ${ }^{1}$, Chris Speed ${ }^{2}$ \\ ${ }^{1}$ Lancaster University,UK; ${ }^{2}$ University of Edinburgh, UK
}

\section{CCS CONCEPTS}

- Social and professional topics $\rightarrow$ Socio-technical systems; • Human-centered computing $\rightarrow$ Mobile computing; • Information systems $\rightarrow$ Collaborative and social computing systems and tools;

\section{INTRODUCTION}

Trust in charitable organisations (NGOs) is on the decline with increasing demands for greater public scrutiny, accountability and transparency in their operations. In parallel, the number of individuals giving money to charities is declining [1]. As a result NGOs have begun to explore new models of giving that can facilitate more trusted relationships between donors and charities[3]. Developed using an experimental, design-oriented approach in close collaboration with international aid organisations we propose a novel event-driven donation framework that leverages emerging distributed ledger technology (DLT) and smart contract capabilities to support real-time, automated conditional donations. Through a mobile user application we demonstrate how donors can be empowered to configure and associate immutable conditions predicated on the occurrence of quantifiable real-world events in order to release pledged funds.

\section{EVENT-DRIVEN DONATIONS}

We define conditional giving as the act of committing to donate funds to a charitable organisation with an associated release clause, rule or condition dependent on the occurrence of a measurable phenomenon [2]. Driven by measurable real-world data, our conditionbased approach supports a large variety of triggers, beneficiaries and data sources, thus it can be adapted to a variety of fundraising campaigns, projects and institutions. The flow diagram (figure 1) provides an overview of stakeholder interactions to configure, sign and validate a Smart Donation. Charities can (i) issue donation templates to define basic parameters (e.g. data-providers, beneficiaries, expiry date), suitable for the affiliated project. Donors (ii) personalise their donation by configuring instances of the donation templates (e.g. duration, amounts, conditions). Once signed (iii) funds are sealed in an escrow on the ledger that neither the donor nor the charity can access. Smart donations (iv) qualified by a data-validator (v) are programmatically enforced and (vi) funds are transferred to the corresponding NGO project.

Permission to make digital or hard copies of part or all of this work for personal or classroom use is granted without fee provided that copies are not made or distributed for profit or commercial advantage and that copies bear this notice and the full citation on the first page. Copyrights for third-party components of this work must be honored

For all other uses, contact the owner/author(s).

HotMobile '20, March 3-4, 2020, Austin, TX, USA

(C) 2020 Copyright held by the owner/author(s)

ACM ISBN 978-1-4503-7116-2/20/03.

https://doi.org/10.1145/3376897.3379161

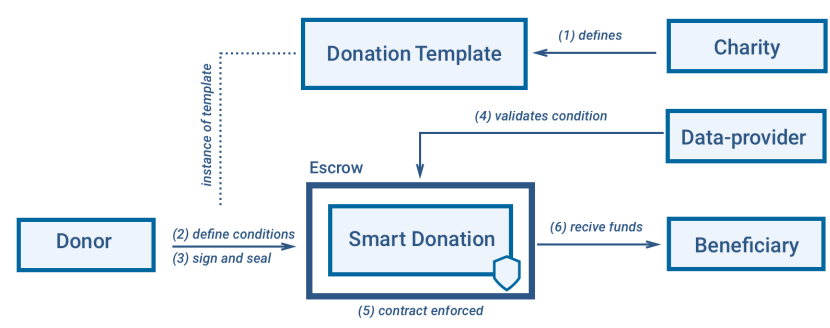

Figure 1: Stakeholder interactions.

A donor, for example, agrees to donate a certain amount to a disaster relief program in the event of a natural disaster. In order to tailor the donation more closely to the donors' needs, they may set conditions relating to the intensity or nature of the event, geographical boundaries (e.g. continents, countries) or the duration. Third-party organisations and agencies, for example the United Nations or the Global Disaster Alert and Coordination System can validate events, and trigger the release of funds in real-time, significantly reducing the time it takes for donations to reach beneficiaries. By leveraging benefits of the underlying DLT, our Smart Donations platform empowers donors to (i) personalise donations by defining conditions relating to real-world phenomena, (ii) store the pledged funds in a secure, transparent and decentralised escrow, and (iii) to automatically release funds to charitable organisations or projects once the donor's conditions have been met.

\section{DEMONSTRATION}

We will demonstrate our mobile application and the underlying architecture and will share our insights in building mobile-first blockchain powered frameworks and applications for the charity sector. We aim to spark discussions about the challenges and lessons learned of making mobile DLT accessible to a broader non-technical audience.

\section{ACKNOWLEDGMENTS}

This research was funded by EPSRC grant EP/N028198/1 - OxChain: Towards secure and trustworthy circular economies.

\section{REFERENCES}

[1] Charities Aid Foundation CAF. 2019. CAF UK giving 2019. (2019).

[2] Chris Elsden, Ludwig Trotter, Mike Harding, Nigel Davies, Chris Speed, and John Vines. 2019. Programmable Donations: Exploring Escrow-Based Conditional Giving. (2019). https://doi.org/10.1145/3290605.3300609

[3] Joshua Hallwright and Elsa Carnaby. 2019. Complexities of Implementation: Oxfam Australia's Experience in Piloting Blockchain. (2019). 